\title{
MÚSICA E PALAVRA NO JARDIM-DE-INFÂNCIA: APRENDENDO CANTANDO HISTÓRIAS
}

\author{
MUSIC AND WORD IN KINDERGARTEN: LEARNING BY SINGING STORIES
}

\author{
Virginie Almeida de Freitas ${ }^{1}$ \\ Colégio Dom Diogo de Sousa - Braga, Portugal \\ viifreitas6@icloud.com \\ António José Pacheco Ribeiro ${ }^{2}$ \\ Conservatório do Vale do Sousa-Lousada, Portugal \\ Universidade do Minho - CIEC - Braga, Portugal \\ antoniopacheco@ie.uminho.pt
}

RESUMO: O projeto Música e Palavra no Jardim-de-Infância: Aprendendo Cantando Histórias, foi desenvolvido no âmbito da Intervenção Pedagógica do Mestrado em Educação PréEscolar, em Portugal, numa sala de quatro anos, num Jardim-de-Infância, e adveio do interesse do grupo de crianças pela música e pela audição de histórias. O objetivo principal do projeto centrou-se no desenvolvimento de atividades relacionadas com a música e com as histórias no sentido de promover competências nas áreas da música e da linguagem. No que concerne às opções metodológicas, recorreu-se, essencialmente, à investigação-ação. Os instrumentos de recolha de informação, centraram-se, principalmente, na observação, nas notas de campo, no registo fotográfico, no registo áudio e no registo audiovisual. No decorrer das atividades, o grupo mostrou-se sempre bastante empenhado e motivado para a construção de novas aprendizagens, quer no âmbito do vocabulário, desenvolvimento da linguagem, imaginação e criatividade, quer no âmbito musical no desenvolvimento cognitivo, afetivo e psicomotor, demonstrando um genuíno interesse pelas histórias e a pela música. Esta intervenção promoveu a cooperação entre o Jardim-de-Infância e a família, sendo a participação ativa dos pais verdadeiramente fundamental. Ao longo do projeto, a temática proporcionou a todos os intervenientes uma partilha de experiências e descobertas riquíssimas.

Palavras-chave: Música e Livros. Histórias. Crianças. Educação-Pré-Escolar.

\footnotetext{
I Licenciada em Educação Básica pela Universidade do Minho. Concluiu o Mestrado em Educação Pré-Escolar, no Instituto de Educação da Universidade do Minho, no ano de 2018. Desde essa altura exerce funções como Educadora de Infância no Colégio Dom Diogo de Sousa.

2 Licenciado em Ensino de Música pela Universidade de Évora e Mestre em Estudos da Criança Especialização em Educação Musical pela Universidade do Minho. Doutorou-se na Especialidade de Educação Musical, em Estudos da Criança, na Universidade do Minho. Leciona no Conservatório do Vale do Sousa, Lousada, e no Instituto de Educação da Universidade do Minho. É membro integrado do Centro de Investigação em Estudos da Criança (CIEC).
} 
ABSTRACT: The project Music and Word in Kindergarten: Learning by Singing Stories was developed in the context of the Pedagogical Intervention of the Master's Degree in Preschool Education in Portugal, in a four-year-old kindergarten class, and came from the interest of the group of children in music and listening to stories. The main objective of the project was centred on the development of activities related to music and stories in order to promote skills in the areas of music and language. As regards the methodological options, action research was essentially used. The instruments for gathering information focused mainly on observation, field notes, photographic, audio and audiovisual recordings. During the activities, the group was always very committed and motivated to the construction of new learning, both in terms of vocabulary, language development, imagination and creativity, and in terms of cognitive, affective and psychomotor development, showing a genuine interest in stories and music. This intervention promoted co-operation between the Kindergarten and the family, with the active participation of the parents being truly fundamental. Throughout the project, the theme provided a rich sharing of experiences and discoveries for all involved.

Keywords: Music and Books. Stories. Children. Preschool education.

\section{Enquadramento teórico \\ I.I O papel da música no processo de aprendizagem da criança}

A linguagem musical deve ser parte integrante de qualquer ambiente educacional, desde a Creche até ao Ensino Secundário, ou mesmo Ensino Superior, isto porque a música oferece, de facto, um ambiente propício para o desenvolvimento cognitivo, auxiliando, inclusive, nas mais diversas atividades. Souza e Joly (2010, p. IoI) citando o Referencial Curricular para a Educação Infantil do Brasil (1998) acrescentam o seguinte:

\footnotetext{
A integração entre os aspetos sensíveis, afetivos, estéticos e cognitivos, assim como a promoção de integração e comunicação social, conferem caráter significativo à linguagem musical. É uma das formas importantes de expressão humana, o que por si só justifica sua presença no contexto da educação, de um modo geral, e na educação infantil, particularmente.
}

Desta forma, é extremamente pertinente que a música esteja presente em contexto escolar, pois é um meio privilegiado para promover o desenvolvimento da criatividade, bem como um "elemento imprescindível na educação, pelo seu valor artístico, estético, cognitivo e emocional. Pedagogicamente, através da criatividade, a linguagem musical oferece possibilidades interdisciplinares, enriquecendo o processo educacional" (CORREIA, 2oIo, p. 197). A música é igualmente um meio fundamental que proporciona às crianças "um largo espectro de experimentação de diferentes capacidades individuais, constituindo um bom meio de experimentação de interações sociais" (COSTA, 2016, p. 14). A referência às interações sociais dá-se, essencialmente, ao facto de a música promover um real convívio entre os colegas do mesmo grupo, privilegiando o sentido de participação, cooperação e, principalmente, de socialização. Para além disso, as crianças pequenas apreciam de facto momentos de grande grupo a cantar músicas variadas. 
As crianças em idade pré-escolar gostam de cantar melodias de todo o tipo, sejam canções de embalar, tradicionais ou populares, ou associadas com festividades e celebrações. A forma como aprendem a cantá-las é por ouvir cantar, juntando-se e cantando vezes sem conta até as canções serem "suas" (HOHMANN; WEIKART, i997, p. 669).

O educador de infância tem um papel fulcral na abordagem e no contacto, desde cedo, das crianças com a música, pois deve ser capaz de proporcionar motivações e formas para desenvolver o sentido musical e satisfazer as necessidades de expressão que o grupo pode encontrar. Num ambiente rico e propício ao contacto com a música, o educador deve "levar as crianças de idade pré-escolar a ouvir uma variedade grande de músicas gravadas e ao vivo" (HOHMANN; WEIKART, 1997, p. 660), dando-lhes, assim, oportunidades para tirar partido da audição e se moverem ao som de melodias de diferentes estilos. O contacto com um maior número de estilos e géneros musicais, não só aumenta o conhecimento das crianças, como, ainda, proporciona a diversidade e expansão do seu universo musical, promovendo o conhecimento e respeito pelas diferentes culturas.

A música tem igualmente uma componente de interdisciplinaridade, no sentido em que podemos trabalhar diversas áreas de conteúdo abordando e utilizando a música com um determinado propósito. A utilização da música como instrumento de aprendizagem é, de facto, uma forma original e diferente de abordar temas de outras áreas de conteúdo.

A possibilidade da professora de educação infantil e anos iniciais trabalhar com a música em suas práticas amplia a capacidade de contextualização e significação a ser construída acerca da música pelos alunos. Na medida em que o professor organiza sua ação pedagógica e articula as áreas de conhecimento, integrando-as à música, as aprendizagens passam a ter mais significado para as crianças (WERLE, 2011, p. 94).

O trabalho de integração e interligação de várias áreas de conteúdo já se faz na Educação Pré-Escolar, por exemplo a trabalhar com o grupo de crianças a linguagem e a literacia com quadras, rimas, trava-línguas ou mesmo canções. Toda esta questão da interdisciplinaridade deixa a refletir, no sentido em que podemos encontrar no nosso percurso crianças com dificuldades numa ou noutra área do saber (Matemática, Expressão e Comunicação) e esta estratégia pode ajudar a motivar a criança para essa determinada área pela qual sente mais dificuldades. O papel do adulto é essencialmente o de orientar, auxiliar e guiar cada criança no que precisar ao longo do seu processo ativo de aprendizagem. Neste sentido, devemos proporcionar um ambiente de belo prazer para que estas aprendizagens aconteçam por parte das crianças.

A música pode e deve ser utilizada em vários momentos do processo de ensinoaprendizagem, sendo um instrumento imprescindível na busca do conhecimento, sendo organizado sempre de maneira lúdica, criativa, emotiva e cognitiva. Os currículos de ensino devem incentivar a interdisciplinaridade e suas várias possibilidades, pois a música ajuda em todas as fases e etapas do ensino (CORREIA, 2010, p. 139).

A música contempla, assim, diversas facetas por si só e pode, com toda a certeza, transforma-se num instrumento metodológico e pedagógico por parte dos educadores. Desta 
forma, a música exerce diferentes funções na nossa sociedade (MERRIAM, 1964) e em específico nas escolas e jardins-de-infância, isto porque a música está presente no quotidiano dos indivíduos e, como já se verificou, desde antes do nascimento, ainda in útero. A música pode ser vista por quem a aborda, trabalha e contacta como uma diversão, ouvir música por prazer; pode ser vista ligada à educação, como forma de transmitir certos novos conhecimentos às crianças ou como forma de trabalhar a literacia e linguagem; a música pode ser vista como um agente de socialização por parte das crianças ou ainda como uma herança cultural. Como se pode constatar, a música pode ser vista de várias formas; este é um dos fatores que torna esta forma de expressão única e extremamente valiosa.

\subsection{Um olhar sobre a relevância das histórias desde os primeiros anos de vida}

Ao terminarmos uma leitura, muito provavelmente, não estaremos iguais a nós mesmos como no começo; ou seja, se o texto passou por nós e foi como uma experiência de leitura, algo ele deixou. Ler como experiência afecta o nosso eu, nos constitui ou põe em questão ou modifica o que somos (BERGMANN; TORRES, 2009, p. 197).

A leitura de histórias e os livros são presença quotidiana nas salas de Jardim-deInfância, sendo atribuído grande valor e incentivo à imaginação, à ampliação do repertório cultural das crianças e ainda à criação de referências extremamente relevantes ao desenvolvimento subjetivo. Esta experiência e contacto com as histórias pelas crianças contribui para uma maior compreensão do mundo que as rodeia. Assim, em várias instituições é promovida a hora do conto para um maior contacto com os livros; esta iniciativa favorece o desenvolvimento da literacia, do carácter lúdico da linguagem, o prazer de ler e a educação estética. De facto, esta atividade deve começar a ter impacto na vida das crianças desde cedo, isto porque como nos refere Veloso (200I, p. 3):

[n]ada, mas mesmo nada, pode substituir a magia e o encanto da descoberta do livro ou das histórias quando as crianças começam a articular as primeiras palavras; sentadas no colo do adulto ou unidos pelo olhar e pela ternura da voz descobrem como é bom comunicar pela palavra, materializada no livro ou nas sonoridades vocais.

Desta forma, a Literatura Infantil deve ter presença nas salas de Jardim-de-Infância e tem, obrigatoriamente, de fazer parte da bagagem profissional do educador de infância, "sob pena de apresentar lacunas inaceitáveis para um bom exercício profissional" (VELOSO, 2001, p. 3). Com esta afirmação o que se pretende enfatizar é o facto do educador de infância não poder descurar a importância e o papel das histórias desde as primeiras etapas da vida da criança. Para além disso, todo o tipo de textos devem fazer parte da vida da criança, como por exemplo o texto poético (lengalengas, trava-línguas, adivinhas, provérbios, quadras e rimas), o texto narrativo (conto popular, lendas, fábulas, romances), e, por fim, o texto dramático. Ainda de acordo com o mesmo autor, podemos reafirmar que:

[e]fectivamente, qualquer criança, para aprender a falar tem de ouvir; haverá algo mais encantador do que a magia da palavra que suporta a lengalenga ou a história contada? Não esqueçamos que o primeiro ano de vida é crucial para o 
desenvolvimento da criança, especialmente a nível neurológico e afectivo, o que não quer dizer que descuremos os anos seguintes - até aos quatro anos grande parte das estruturas estão consolidadas (VELOSO, 2001, p. 2-3).

Como se tem vindo a referir, a riqueza das narrativas presentes nos livros desenvolve a imaginação das crianças, mas não nos podemos esquecer do desenvolvimento do pensamento lógico e organizativo, relativamente à estrutura temporal da história. Através dessas mesmas narrativas, as crianças aprendem e passam a dar sentido e significado às diferentes situações quotidianas vividas, bem como, a entenderem diversos sentimentos e emoções.

Todos sabemos o quanto a leitura e a escrita se tornaram fundamentais nos nossos dias, para todos os indivíduos de uma sociedade; precisamos da leitura até para pequenas tarefas do quotidiano que realizamos de forma inconsciente. É evidente que estamos a referir que precisamos da leitura para tudo, desta forma, é importante que as crianças tenham a clara noção do quanto é necessária a linguagem escrita. Relativamente à afirmação supracitada, não nos estamos a referir nunca a um ensino formal da leitura e da escrita, a partir do Jardim-de-Infância, mas apenas a um trabalho mais detalhado, intencional e direcionado para a literacia emergente, como forma de motivar as crianças desde cedo. De facto, o educador de infância pode influenciar o caminho e o percurso de cada criança de forma individualizada, para que esta crie hábitos de leitura imprescindíveis desde o berço e se torne um leitor competente.

Ao proporcionar modelos para um discurso organizado, ao fornecer exemplos de frases mais complexas, ao permitir o alargamento do vocabulário da criança e a construção de novos significados, a actividade de ler e contar histórias a crianças, contribui, decisivamente, para aumentar os seus conhecimentos sobre todos os aspectos da língua. Este desenvolvimento linguístico influencia o desenvolvimento das capacidades da leitura e da escrita que, por sua vez, interagem com a linguagem, determinando um tanto maior desenvolvimento linguístico como da leitura e da escrita (VILLAS-BOAS, 2002, p. 8I).

Nesse sentido, todas as ocorrências com a leitura de histórias e com experiências com a escrita, antes da instrução formal, estão intimamente relacionadas com um maior aproveitamento na leitura para o futuro da criança. Realmente, estamos em condições de afirmar que com as histórias, ao mesmo tempo que a criança é preparada para a leitura e a escrita, cresce igualmente a oportunidade de se desenvolver o espírito crítico tendo inúmeras vantagens para as crianças, como por exemplo: aprender a ler, gostar de ler, transmutar conhecimentos em saberes, adquirir competências e, ainda, formar-se com o que se lê. $\mathrm{Na}$ realidade, é importante dar atenção às histórias infantis e retirar delas todo o aproveitamento possível, porque estas concorrem significativamente para o processo de ensino $\mathrm{e}$ aprendizagem das crianças. Nesta mesma linha de pensamento, é importante acrescentarmos que "a leitura conjunta de livros de histórias é vista como um instrumento poderoso, pois proporciona um contexto interactivo que é contextualizado, autêntico e significativo, interessante e motivante para as crianças em idade pré-escolar" (LEAL; GAMELAS; PEIXOTO; CADIMA, 2014, p. I79). 


\section{I.3 Música e palavra - unindo histórias e música}

A Música e a Literatura Infantil fazem parte do dia-a-dia de um Jardim-de-Infância; desta forma é óbvio afirmar que as duas práticas se podem unir e tornarem-se práticas comuns no quotidiano da Educação Pré-Escolar. Na verdade, as histórias são um ótimo meio para o desenvolvimento de atividades de diferentes áreas de conteúdo, principalmente atividades ligadas à área da expressão musical. Deste modo, o trabalho com histórias, pode muitas vezes significar a integração e o envolvimento de diversas linguagens que englobam essencialmente a área da arte, como por exemplo com o teatro aquando de uma dramatização de uma história, e ainda da dança e expressão plástica. Reys (20II, p. 69) refere que "atividades com histórias são um meio eficiente de desenvolver conteúdos musicais, envolvendo e motivando as crianças para o fazer musical”. A mesma autora (p. 70) ainda acrescenta que "as histórias representam um meio eficiente de se trabalhar conteúdos musicais, como perceção, caráter expressivo e forma, o uso da voz e o manuseio de instrumentos, a partir de atividades consideradas prioritárias no processo de desenvolvimento musical dos alunos". Para além disso, tem-se ainda oportunidade de considerar várias possibilidades que a união de histórias e de música podem desenvolver. Sendo assim, entre muitas possibilidades, podemos referir o desenvolvimento da criatividade, da responsabilidade com o grupo, a socialização e a afetividade, o favorecimento da livre expressão de ideias, bem como o favorecimento de debates e discussões entre o grupo.

A prática de utilizar histórias, desenvolvendo atividades a partir dos livros, é uma forma única de interagir com o grupo e uma forma de auxiliar cada criança a criar e a recriar um mundo imaginário. "[...] é bom lembrar que as histórias se constituem em passagens para mundos imaginários, para culturas distantes com personagens, sons e melodias que encantam crianças e adultos" (REYS, 20II, p.7I). Neste sentido, a música tem uma íntima ligação com as histórias, isto porque está intrinsecamente em cada história e em cada verso. Por muito que não nos apercebamos disso, a Literatura Infantil contempla um enorme universo a ser explorado pela Música, como por exemplo, as quadras, as rimas, os poemas, os trava-línguas e ainda as lengalengas. Desta forma, “[...] utilizando-se dos sons das palavras para participar do imaginário da criança; ao mesmo tempo a história se faz presente na música para compor um mundo de faz-de-conta que beneficia a formação lúdica, a capacidade de brincar, cantar e improvisar" (SHUNEMANN; MAFFIOLETTI, 2oIr, p. I29). Reys (20II, p. 72) diz-nos que "autores da área de educação musical ressaltam a importância da história no dia-a-dia das crianças como meio de desenvolver a escuta e a fala, além de promover reflexões sobre questões afetivas e valores”. De facto, unir histórias com a música pode possibilitar diversas experiências práticas para o grupo, como por exemplo, a criação de músicas, de poemas ou quadras a partir de um livro. Pode-se ainda acrescentar, que criar ambientes sonoros por parte do educador, criar cenários, dramatizações, ações e diálogos que girem à volta de histórias, amplia o desenvolvimento cognitivo da criança, bem como a sua participação ativa enquanto principal agente do processo educativo.

Quando a música conecta-se com a história aproveita dela a magia, a força do enredo, e a concretude das sequências dos acontecimentos do enredo. Por outro lado, a história se enriquece com a inserção da música que marca e acentua pontos 
decisivos do desenrolar da história. A música amplia a sonoridade das histórias, acentuando a ênfase e valoriza as nuances da interpretação, permitindo o duplo efeito de oferecer à criança uma história com música e a música com história. Revelam assim a interdependência e complementaridade que cria o eixo pedagógico: um está entrelaçado no outro (SHUNEMANN; MAFFIOLETTI, 2011, p. 129).

É importante mencionar nesta fase, que o momento de contar histórias ou a leitura de um livro é de uma importância significativa para as crianças; esse momento favorece um enorme envolvimento por parte de todos os participantes; a forma musical como a educadora irá ler uma história, é um fator decisivo para a ligação e o empenhamento de todo o grupo. $\mathrm{O}$ envolvimento e o empenhamento por parte das crianças, pode acontecer porque a sonoridade e o ritmo da leitura da história forma uma fluência que se parece com uma canção. Deste modo, aquando da leitura da história, é importante complementar com movimentos corporais, sons, canções, a exploração de ritmos e timbres e de sons onomatopeicos.

A contação de histórias na educação infantil é sempre um momento significativo de aprendizado da turma. Através da expressão corporal, da interpretação e técnica vocal, a forma de contar a história torna-se envolvente, cativante e emocionante para as crianças, incentivando-as à leitura e estimulando a imaginação. As crianças participam do enredo da história a ponto de imaginarem-se os próprios personagens. O exercício de envolver os alunos na história e proporcionar atividades de desenho, teatro e músicas sobre o livro complementa a contação (PONSO, 2011, p.98).

Contar histórias pressupõe um real envolvimento do contador de histórias; para além disso, as trocas que são realizadas durante a leitura transcendem a linguagem oral, isto porque, inclui olhares, respiração, expressão, emoções geradas pela narração (o medo, o suspense, a alegria, o entusiasmo, ...). Unir histórias e músicas "possibilita ao aluno explorar sua autonomia, desenvolvendo e exercitando sua memória, seu raciocínio, sua capacidade de perceção e sua criatividade", irá, desta forma, influenciar no tipo de indivíduo que a criança se irá tornar, tornando-o criativo com um papel importante no funcionamento da sociedade, "pois é ele quem faz as descobertas, inventa e promove mudanças" (BERGMANN; TORRES, 2009, p. 197). Neste sentido, o educador deve sempre pensar numa organização do ambiente educativo de forma intencional e planeada, pensada e contextualizada, que permita a realização de atividades de narração de história e atividades ligadas à música para que de uma forma ou de outra, consiga unir as duas práticas a fim de envolver ainda mais as crianças num processo rico de conteúdos e de aprendizagem.

\section{Metodologias de investigação e de intervenção 2.I Dimensão investigativa: investigação-ação}

A dimensão investigativa utilizada durante o desenvolvimento do projeto foi a investigação-ação, porque representa um ato físico de investigar, um ato prático que nos leva a examinar com um envolvimento dinâmico. Este processo de investigação-ação implica que 
o educador ou professor não se limite a um mero papel passivo, consumindo apenas as investigações realizadas por outros profissionais.

O educador-investigador deve passar de um objeto da investigação dos académicos (outros profissionais) a sujeito da sua própria investigação, como forma de conhecer e trabalhar em prol de uma melhoria do ambiente educativo. "A investigação-acção parte do pressuposto de que o profissional é competente e capacitado para formular questões relevantes no âmbito da sua prática, para identificar objectivos a prosseguir e escolher as estratégias e metodologias apropriadas para monitorizar tanto os processos como os resultados" (OLIVEIRA-FORMOSINHO; FORMOSINHO, 2008, p. 9- io). Neste processo, o educador é visto enquanto ator que assume uma postura de permanente questionamento, operacionalização, documentação e profunda reflexão profissional acerca de todos os aspetos da investigação. De facto, a investigação-ação torna-se um real desafio para o profissional, que deve desenvolver todo este processo de forma cooperada, pois é um processo que acontece na prática. A investigação-ação consiste, essencialmente, numa recolha de informação sistemática com o objetivo de promover mudanças. Nesse sentido, toda a recolha de informação e de dados para o projeto desenvolvido foi feita no local da investigação com um envolvimento ativo e exaustivo na procura de materiais e de documentação.

A investigação e a ação podem e devem caminhar juntas, isto quando se pretende realmente uma transformação da prática. A investigação consegue aumentar a compreensão do investigador, e a ação, obtém a mudança daquilo que o investigador pretende. Desta forma, a direção a tomar, o sentido, a intencionalidade dessa transformação são os eixos que caracterizam a investigação-ação. De acordo, com Bogdan e Biklen (1994, p.292), "a investigação é uma atitude - uma perspectiva que as pessoas tomam face a objectos e actividades. Académicos e investigadores profissionais investigam aspectos pelos quais nutrem interesse. Formulam o objectivo do seu estudo, em forma de hipóteses ou de questões a investigar”. Nesta linha de pensamento, é necessário manter uma atitude colaborativa, reflexiva, prática, participativa e acima de tudo, investigativa.

\subsection{Instrumentos e técnicas de recolha de informação}

A investigação-ação apresenta um conjunto de características fundamentais para o desenvolvimento de um projeto, tais como: planear, agir, refletir, avaliar e dialogar. Sendo assim, é essencial ter-se em conta certos instrumentos e técnicas de recolha de informação para a realização desses ciclos da investigação-ação. Os instrumentos de recolha de dados desta investigação foram os seguintes: a observação, as notas de campo, o registo fotográfico e de vídeo, e o registo áudio.

\section{Observação:}

A observação, durante todo este projeto de intervenção, apresentou-se como um instrumento de recolha de dados (documentação) de extrema importância. Deste modo, "observar o que as crianças fazem, dizem e como interagem e aprendem constitui uma estratégia fundamental de recolha de informação" (SILVA, 2016, p. 13). Para uma concretização de um projeto fiável, é necessária uma constante recolha de dados, para mais tarde conseguir-se realizar uma avaliação precisa do mesmo. 


\section{Notas de campo:}

As notas de campo foram utilizadas por serem uma estratégia extremamente útil, isto porque, são consideradas um "relato escrito daquilo que o investigador ouve, vê, experiencia e pensa no decurso da recolha e reflectindo sobre os dados2 (BOGDAN; BIKLEN, 1994, p. 150). Os mesmos autores, ainda referem que as notas de campo podem originar uma espécie de diário pessoal, que irá ajudar o investigador a acompanhar todo o desenvolvimento do projeto, a visualizar como é que o plano de investigação foi afetado pelos dados recolhidos e, principalmente, a tornar-se consciente do trabalho realizado. Será igualmente relevante dizer, que as notas de campo são contempladas por dois aspetos: o descritivo e o refletivo. Foi desta forma, possível, durante o projeto, realizar longas descrições das atividades e, posteriormente, realizar uma reflexão sobre essas mesmas atividades para perceber os detalhes que ocorreram no campo.

\section{Registo fotográfico e de vídeo e registo áudio:}

Os registos fotográficos e de vídeo, deste projeto, foram realizados pela própria investigadora no decorrer de todas as atividades. Estas são duas técnicas de recolha de informação que nos dão dados descritivos extremamente relevantes para as nossas avaliações; por exemplo, conseguimos perceber o estado de espírito da criança, se estava participativa, envolvida, empenhada, ou então se não estava a gostar da atividade, perceber as suas expressões, reações e comportamentos. $O$ registo audiovisual durante o estágio foi bastante utilizado enquanto observadora, no sentido que oferecia diversas pistas de como as crianças se estavam a comportar e permitia fazer reflexões profundas. As gravações de áudio também foram utilizadas e tal como os vídeos e as fotografias fornecem pistas sobre as relações e as nossas atividades.

\section{Procedimentos e objetivos}

O tema do projeto Música e Palavra no Jardim-de-Infância: Aprendendo Cantando Histórias adveio do interesse do grupo de crianças, por mim identificado, pela música e pela audição de histórias; nesse sentido, considerei pertinente que a escolha do tema ligasse intimamente a música e as histórias. Os principais objetivos definidos para a elaboração deste projeto foram os seguintes: (i) potenciar o contacto com diversas formas de expressão e comunicação; (ii) proporcionar às crianças meios e motivações para desenvolverem o seu sentido musical; (iii) promover momentos lúdicos e de aprendizagem em torno dos livros; (iv) averiguar o contributo das histórias na vida das crianças; (v) averiguar o papel da música e o seu contributo na Educação Pré-Escolar; (vi) dinamizar a área da biblioteca na sala dos 4 anos.

Durante o período de observação surgiram duas ideias que guiaram toda a realização deste trabalho: A Fada das História e A Maleta Viajante. Nesse sentido, estas duas ideias foram parte integradora do trabalho desenvolvido o que o torna ainda mais relevante. A Fada das Histórias foi uma personagem que decidi criar para motivar o grupo para a audição de histórias, isto porque, antes de iniciar o projeto tinha decidido abordar quatro livros de Literatura para a Infância (O Urso e o Piano de David Litchfield; Bernardino de Manuela Bacelar, O Monstro das Cores de Anne Llenas e Meu Coração Pequenino de Jo Witek) e com 
esses livros realizar atividades que integrassem as diversas Áreas de Conteúdo e que, essencialmente, incidissem sobre a Literacia/Linguagem e a Música. No entanto, pareceume que essa abordagem mais simplista necessitava de um fator inovador para cativar todo o grupo, foi então que surgiu A Fada das Histórias, mais especificamente, a fada Carlota, que acompanhou o grupo na realização de todas as atividades e ao longo de todo o projeto. Esta personagem, totalmente imaginária, entrava dentro da sala dos 4 anos e deixava pistas: livros trabalhados com o grupo; missões e cartas para as crianças, sempre com o intuito de envolver os participantes do projeto. A segunda ideia: A Maleta Viajante, surgiu igualmente no momento de observação e reflexão, antes de iniciar a implementação do projeto, com a intenção das crianças criarem a sua própria história com a ajuda dos pais. É fundamental mencionar que essa maleta foi introduzida pela fada Carlota com uma missão a realizar pelas crianças, sempre com o propósito de criar um fio condutor entre estas duas ideias. Os principais objetivos da realização de A Maleta Viajante foram: promover a criação de histórias, estimular a imaginação e a criatividade das crianças e, acima de tudo, criar um verdadeiro envolvimento dos pais no percurso de aprendizagem dos seus filhos.

\section{Resultados}

Ao longo de todo o trabalho desenvolvido tentei promover o envolvimento das crianças em torno do projeto, das atividades desenvolvidas, e, essencialmente, em torno da personagem fictícia, Fada Carlota, que se mostrou essencial e de um carácter motivador para o grupo. De acordo com todos os dados recolhidos, como por exemplo, notas de campo, diálogos com as crianças, pequenas reflexões, vídeos e áudios, foi possível perceber que o grupo se mostrou desde o início, cativado, empenhado, envolvido e interessado pela personagem criada. Esta ideia, A Fada das Histórias, possibilitou momentos de jogo simbólico, momentos de fantasia e magia, momentos de estimulação da imaginação, criatividade e curiosidade. Com o desenrolar do projeto, e suas atividades propostas, foi possível proporcionar às crianças vivenciar múltiplas experiências, utilizar várias formas de comunicação, novos conhecimentos e sensações, tornando todo o ambiente educativo num espaço de aprendizagem pela ação ou aprendizagem ativa. Durante as atividades desenvolvidas tive a oportunidade de trabalhar com o grupo, quadras, com o objetivo de desenvolver a consciência fonológica, mas também a Literacia Musical; tive oportunidade de desenvolver atividades de expressão rítmica, dança e movimento (expressão corporal) ao som de grandes compositores; foi possível abordar os sentimentos e as emoções, para que as crianças aprendessem a expressar-se e a saber dialogar sobre o que sentiam.

Em paralelo com a ideia, A Fada das Histórias, desenvolvi outra iniciativa, intitulada A Maleta Viajante. Esta iniciativa, foi planeada a pensar nas crianças do grupo, em particular nos seus interesses pelas histórias. Esta abordagem permitiu que as crianças desenvolvessem a sua criatividade - ao criarem uma história; a partilha - por permitir que as crianças partilhassem a maleta, e esta passasse pela casa de todos; o respeito e a responsabilidade por se tornarem responsáveis pela maleta; a autoestima - ao fazer perceber às crianças que eram capazes de criarem/inventarem uma história. A Maleta Viajante baseou-se igualmente na cooperação entre o Jardim-de-Infância e a família, sendo a participação ativa dos pais, um dos pontos mais relevantes de toda a iniciativa. Deste modo, a participação das famílias apresentou-se como uma verdadeira vantagem para motivar automaticamente o grupo, pois 
conseguiram despertar o interesse de todas as crianças mais facilmente. $\mathrm{O}$ culminar de $A$ Maleta Viajante foi de facto a realização do concerto por parte das crianças, acompanhadas por músicos profissionais. Apesar do objetivo, desde cedo, fosse dramatizar a história que as crianças tinham inventado com a ajuda dos pais, não foi possível concretizar essa ideia e, nesse sentido, foi necessário substituir a dramatização por um concerto. Como a história criada pelas crianças e as suas famílias, terminava com um concerto dado pelas personagens principais da história, achei que faria sentido realizar apenas o concerto final. Apesar da ideia A Maleta Viajante não ter acabado com a dramatização, tal como eu idealizava desde o início, posso afirmar que o concerto foi sem dúvida um dos momentos altos do Projeto Pedagógico desenvolvido com o grupo.

\section{Considerações finais}

A implementação do projeto Música e Palavra no Jardim de Infância: Aprendendo Cantando Histórias permitiu-me concluir que com o estudo da temática e a realização das atividades, consegui perceber o contributo e a importância das histórias e da música na vida das crianças, no seu desenvolvimento e processo de aprendizagem. Nesse sentido, as histórias e a forma como foram abordadas com o grupo, proporcionaram aprendizagens em diferentes níveis: aquisição de novo vocabulário, desenvolvimento da linguagem oral e do discurso oral, aumento da imaginação e criatividade, maior perceção da estrutura das histórias, maior poder argumentativo e crítico. Relativamente à música e ao seu contributo, mostrou-se ser um fator extremamente relevante no desenvolvimento cognitivo, afetivo e psicomotor das crianças. Compreendi com toda a certeza, que a música apelou intrinsecamente ao interesse das crianças, levando-as a exprimirem-se acerca do que ouviam e a movimentarem-se livremente pelo espaço ao som da música. Desta forma, o impacto do Projeto Pedagógico no grupo e no seu desenvolvimento foi notório; os objetivos prédefinidos foram cumpridos e o ambiente educativo criado foi estimulante e desafiante ao ponto de proporcionar múltiplas oportunidades e possibilidades às crianças de contactarem com Música e Literatura para a Infância. As crianças adquiriram e desenvolveram aprendizagens através de interações: criança-criança, criança-equipa educativa e criançafamília.

\section{Referências}

BERGMANN, Leila Mury.; TORRES, Maria Cecília. Vamos cantar histórias? Conjectura: Filosofia e Educação, v. I4, n. 2, p. 187-201, maio/ago. 2009. Disponível em: $\langle$ http://www.ucs.br/etc/revistas/index.php/ conjectura/article/view/23/22〉. Acesso em: 28 nov. 2018.

BOGDAN, Robert; BIKLEN, Sari. Investigação Qualitativa em Educação - Uma introdução à teoria e aos métodos. Porto: Porto Editora, 1994. 336 p.

CORREIA, Marcos António. A função didático-pedagógica da linguagem musical: uma possibilidade na educação. Educar, Curitiba, Editora UFPR, n. 36, p. 127-I45, 2010. 
COSTA, Irene Cortesão. A música no Jardim-de-Infância. Projeto "Crescer com a música" da Câmara Municipal do Porto. Porto: Escola Superior de Educação Paula Frassinetti, 2016. $46 \mathrm{p}$.

HOHMANN, Mary; WEIKART, David. Educar a Criança. Lisboa: Fundação Calouste Gulbenkian, 1997. 824 p.

LEAL, Teresa; GAMELAS, Ana Madalena; PEIXOTO, Carla; CADIMA, Joana. Linguagem e literacia emergente. Propostas de intervenção em jardim de infância. In: VIANA, Fernanda Leopoldina; RIBEIRO, Iolanda; BAPTISTA, Adriana. (Coord.). Ler para ser: os caminhos antes, durante e... depois de aprender a ler. Coimbra: Edições Almedina, 2014. p. 175-205.

MERRIAM, Alan. The Anthropology of Music. Ilinois: University Press, 1964. 37I p.

OLIVEIRA-FORMOSINHO, Júlia; FORMOSINHO, João. Prefácio. In: MÁXIMOESTEVES, Lídia. Visão panorâmica da Investigação-Acção. Porto: Porto Editora, 2008. p. 7-I4.

PONSO, Caroline Cao. Poemas, parlendas, fábulas, histórias e músicas na literatura

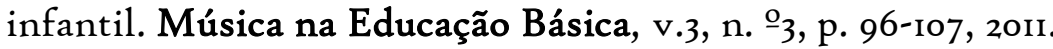

REYS, Maria Cristiane Deltregia. Era uma vez ... Entre sons, músicas e histórias. Música na Educação Básica, v.3, n. ${ }^{\circ}$, p. 68-83, 2011.

SCHÜNEMANN, Aneliese Thönnigs; MAFFIOLETTI, Leda de Albuquerque. Música e histórias infantis: o engajamento da criança de o a 4 anos nas aulas de música. Revista da

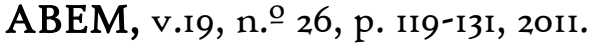

SILVA, Isabel Lopes da (Coord.). Orientações Curriculares para a Educação Pré-Escolar. Lisboa: Ministério da Educação, 20ı6. ıı p.

SOUZA, Carlos Eduardo de; JOLY, Maria Carolina Leme. A importância do ensino musical na educação infantil. Cadernos da Pedagogia, v. 4, n.o 7, p. 96-ıı, jan-jun. 20 o.

VELOSO, Rui Marques. Curtir Literatura Infantil no Jardim-de-Infância. In: ENCONTRO NACIONAL DE INVESTIGAÇÃO EM LEITURA, LITERATURA INFANTIL E ILUSTRAÇÃO, II, 20oI, Coimbra. Anais [...]. Coimbra, 2ooI, p.i-6. Disponível em: $\langle$ http://www.casadaleitura.org/portalbeta/bo/documentos/ot_li_jardinf_rveloso_a.pdf $\rangle$. Acesso em: 27 mar. 202I.

VILLAS-BOAS, Maria Adelina. Leitura de histórias: o contributo da dimensão sócioafetiva. In: VIANA, Fernanda Leopoldina; MARTINS, Marta; COQUET, Eduarda. 
Leitura, Literatura Infantil e Ilustração: investigação e prática docente. Braga: Bezerra Editora, 2002. p. 80-9I.

WERLE, Kelly. Sonorizando histórias e discutindo a educação musical na formação e nas práticas de pedagogos. Música na Educação Básica, v.3, n. ำ 3, p. 84-95, 2011. 